NASA Technical Memorandum 107399

AIAA-97-0303

\title{
Tests of the Performance of Coatings for Low Ice Adhesion
}

David N. Anderson

Lewis Research Center

Cleveland, Ohio

and

Allen D. Reich

BFGoodrich R\&D Center

Brecksville, Ohio

Prepared for the

35th Aerospace Sciences Meeting \& Exhibit

sponsored by the American Institute of Aeronautics and Astronautics

Reno, Nevada, January 6-10, 1997

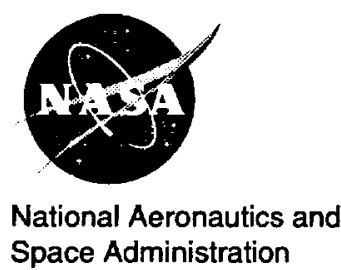


$1 \mathbf{1}$ 


\author{
Tests of the Performance of Coatings for Low Ice Adhesion \\ David N. Anderson \\ NASA Lewis Research Center \\ Cleveland, Ohio \\ and \\ Allen D. Reich \\ BFGoodrich R\&D Center \\ Brecksville, Ohio
}

\begin{abstract}
This paper reports studies of the performance of low-iceadhesion coatings by NASA Lewis and BFGoodrich. Studies used impact ice accreted both in the NASA Lewis Icing Research Tunnel (IRT) and in the BFGoodrich Icing Wind Tunnel (IWT) and static ice in a BFGoodrich benchtop parallel-plate shear rig. Early tests at NASA Lewis involved simple qualitative evaluations of the ease of removing impact ice from a surface. Coated surfaces were compared with uncoated ones. Some of the coatings were tested again with static ice at BFGoodrich to obtain quantitative measurements. Later, methods to establish the adhesion force on surfaces subjected to impact ice were explored at Lewis. This paper describes the various test programs and the results of testing some of the coatings evaluated over the past 5 years. None of the coatings were found to be truly ice-phobic; however, the most effective coatings were found to reduce the adhesion of ice to about $1 / 2$ that of an uncoated aluminum surface.
\end{abstract}

\section{Nomenclature}

$\begin{array}{ll}A & \text { Surface area, } \mathrm{m}^{2} \\ A_{d} & \text { Adhesive Strength, } \mathrm{nt} / \mathrm{m}^{2} \\ F & \text { Force, } \mathrm{nt} \\ L W C & \text { Liquid-water Content, } \mathrm{g} / \mathrm{m}^{3} \\ M W D & \text { Median Volume Droplet Diameter, } \mu \mathrm{m}\end{array}$

\section{Introduction}

This paper describes tests performed to compare the adhesion of ice on uncoated aluminum with that on surfaces with various coatings. Most of the tests described here have been performed on impact ice in icing tunnels at NASA Lewis Research Center and at BFGoodrich Aerospace. Because static ice has different structure and properties from impact ice, tests were also made with static ice using a BFGoodrich bench-top shear rig to compare with the impact-ice results.

NASA Lewis has performed icing research for over 50 years, operating the world's largest refrigerated icing tunnel, the Icing Research Tunnel (IRT). During that time numerous requests have been received from organizations ranging in size from individual inventors to large corporations to test "ice-phobic" coatings that the sponsor believed would prevent ice from adhering to aircraft surfaces. Such requests have been accomodated whenever tunnel schedule permitted, because the development of lowadhesion coatings has always been viewed as having the potential to improve the performance of ice-protection systems.

BFGoodrich Aerospace manufactures pneumatic-boot iceprotection systems, the oldest and most widely-used system for protecting aircraft component leading edge surfaces from in-flight ice accretion. The boot works by periodically inflating to break the bond of accreted ice with the surface and lifting the ice so that the airflow over the surface can carry the shattered ice pieces away. If the adhesion of the ice to the surface of the boot could be reduced, the energy required to break the ice-surface bond could be reduced as well. There are two primary benefits of reducing ice adhesion: ice protection systems requiring lower energy could be used and the removal of ice would be cleaner. Because of the potential benefits in ice-protection system performance, BFGoodrich maintains an interest in thedevelopment of low ice-adhesion coatings. ${ }^{1-3}$

Early studies of static-ice adhesion to surfaces were performed by Loughborough and Haas ${ }^{1}$ and by Loughborough ${ }^{2}$. They evaluated the different parameters which affected ice adhesion and found that the adhesion strength increased linearly with decreasing temperature. In these studies, silicones reduced the adhesion of ice, but a small layer of silicone was stripped away with each ice removal, so this was not a permanent coating. Loughborough and Haas ${ }^{1}$ noted that a poor correlation exists between low ice adhesion and water repellancy.

Results from simple evaluations of coated surfaces performed by NASA Lewis before the studies given here have not been published. However, anecdotal reports from these tests have indicated that while ice adhesion to greased surfaces appeared to be nearly zero, aerodynamic forces held the ice in place and permitted it to accrete normally".

Scavuzzo and $\mathrm{Chu}^{5}$ and Scavuzzo, Chu and Kellackey ${ }^{6}$ have made extensive studies of ice accretion along with other properties of impact ice. They found no effect of 
accretion temperature over the range of $-22^{\circ} \mathrm{C}\left(-8^{\circ} \mathrm{F}\right)$ to about $4^{\circ} \mathrm{C}\left(25^{\circ} \mathrm{F}\right)$ with a linear decrease in adhesive shear stress from $-5^{\circ} \mathrm{C}\left(23^{\circ} \mathrm{F}\right)$ to $0^{\circ} \mathrm{C}\left(32^{\circ} \mathrm{F}\right)$. They also reported that adhesive shear stress increases slightly with increasing airspeed and increasing droplet size.

Recently, Reich ${ }^{3}$ reported static ice adhesion to silicone coatings on a neoprene substrate; measurements were made using a parallel-plate shear test apparatus. He performed multiple ice removals to establish the stability of the coating with respect to repeated deicing. Reductions in shear strength up to a factor of 10 compared with untreated neoprene were demonstrated. For some coatings, the shear strength increased with repeated ice removals, while for others, it decreased. Explanations were proposed for the mechanisms for these behaviors. Silicone grease was found to exhibit icephobic characteristics initially, but shear strength increased rapidly with repeated ice removals. Rain erosion was shown to increase ice adhesion significantly, even for short exposure times. Thus, while very low adhesion is possible, durability must be demonstrated both for repeated ice removals and for rain impingement at aircraft speeds.

\section{Test Facilities}

NASA Lewis Icing Research Tunnel The NASA Lewis Icing Research Tunnel (IRT) has been described in reference 7. The IRT has a test section width of $2.7 \mathrm{~m}(9$ $\mathrm{ft}$ ) and a height of $1.8 \mathrm{~m}(6 \mathrm{ft}$ ) With a model blocking $5 \%$ of the test-section cross-sectional area, airspeeds up to 160 $\mathrm{m} / \mathrm{s}$ (350 mph) can be achieved. A refrigeration system provides control of the test-section temperature from -30 to $1^{\circ} \mathrm{C}\left(-20\right.$ to $\left.33^{\circ} \mathrm{F}\right)$ within $\pm .5^{\circ} \mathrm{C}\left( \pm 1^{\circ} \mathrm{F}\right)$. The water-spray system has 8 spray bars and is used with either of two sets of spray nozzles, known as the NASA standard and mod-1 nozzles. The droplet median volume diameter has been calibrated over the range of 15 to $40 \mu \mathrm{m}$ and the test-section liquid-water content, from .2 to $3.4 \mathrm{~g} / \mathrm{m}^{3}$. For the tests reported here, the mod-1 nozzles were used.

\section{BFGoodrich Icing Wind Tunnel The BFGoodrich Icing}

Wind Tunnel (IWT) has a test section width of $56 \mathrm{~cm}$ (22 in) and a height of $112 \mathrm{~cm}(44 \mathrm{in})$. Test-section airspeeds can be varied from $13 \mathrm{~m} / \mathrm{s}$ ( $30 \mathrm{mph}$ ) to $103 \mathrm{~m} / \mathrm{s}$ (230 mph). Test-section temperatures can be controlled to within \pm $.5^{\circ} \mathrm{C}\left( \pm 1^{\circ} \mathrm{F}\right)$ in the range of -30 to $0^{\circ} \mathrm{C}\left(-22\right.$ to $\left.32^{\circ} \mathrm{F}\right)$. The water-spray system uses 7 spray bars. The use of either NASA standard or mod-1 nozzles gives test-section droplet median volume diameters controllable from 5 to $50 \mu \mathrm{m}$ with liquid-water contents in the range of .1 to $3 \mathrm{~g} / \mathrm{m}^{3}$.

\section{Summary of Test Techniques and Results}

Through the years, several approaches have been used to evaluate low-adhesion coatings. Table 1 is a summary of the experimental methods used by NASA Lewis and the coatings tested in the past 5 years. In addition to these tests, studies of particular coatings have been performed by BFGoodrich as part of a joint effort to identify coatings effective for ice-protection systems. The studies and their results will be described here.

Qualitative Tests in the IRT Early tests of coatings in the IRT tended to be somewhat casual, with few or no measurements of performance and no published reports of the results. The simplest tests in the IRT involved inserting a specimen coated with a believed "ice phobic" into the tunnel to determine if ice would accrete. These tests can often be performed at the same time as another test in the tunnel test section. Test coatings have included a variety of materials, including greases, several forms of teflon and diamond-like coatings (DLC). These tests showed that ice accretes even on a "zero"-adhesion surface such as grease, and for many inventors who believed they had developed an ice-phobic, the demonstration of ice accreting on their coating has been very educational. These tests showed that while the adhesion of ice may be reduced significantly compared with an uncoated surface, the aerodynamic forces present in flight will hold an ice formation in place. It became apparent that zero ice adhesion was not a practical goal for in-flight ice protection, but that reduced adhesion might be helpful in improving the performance of ice-protection systems.

Comparitive Tests With 7.6-cm Cylinders in IRT Later tests recorded ice shapes as well as subjective impressions of the effort required to remove ice from coated and uncoated surfaces. Tests were made using 7.6-cm- (3-in-) diameter hollow aluminum cylinders mounted vertically in the tunnel test section as shown in Figure 1(a). Several cylinders were prepared with different coatings, but cylinders were tested individually. Each cylinder had three 7.6-cm- (3-in-) wide bands which could be coated; the coated bands were separated by $5-\mathrm{cm}$ (2-in) widths of uncoated aluminum. The test cylinder was mounted such that the middle of the center band was at the tunnel centerline. It is at the tunnel centerline that the cloud calibration applies; positions away from the centerline may experience slightly different liquid-water contents.

Ice was accreted on these cylinders at static temperatures of $-1,-4$ and $-18^{\circ} \mathrm{C}\left(30,25\right.$ and $\left.0^{\circ} \mathrm{F}\right)$, test-section velocities of 45 and $112 \mathrm{~m} / \mathrm{s}$ ( 100 and $250 \mathrm{mph}$ ), water droplet medianvolume diameters of 15,25 and $40 \mu \mathrm{m}$ and liquid-water contents of $.5,1$ and $1.8 \mathrm{~g} / \mathrm{m}^{3}$. Spray times were adjusted depending on test conditions to maintain a constant ice accumulation; times varied from 5 to 25 minutes. At the 
completion of the spray, a heated aluminum plate was used to melt a 6.4-mm (1/4-in) gap through the ice at each of the coated portions of the cylinder as well as at an uncoated strip. Ice shapes were then recorded by inserting a cardboard template into each gap and tracing the outline of the ice. Finally, the ice growth on each coated band was isolated by melting additional thin gaps in the ice at the top and bottom of each band; a subjective assessment of the ease with which the ice could be removed was obtained by striking a light blow to the ice with a teflon rod.

Among the coatings tested were a hydrophobic treatment for aircraft windshields (PPG Surface Sealm), a Dow Chemical "Anti-Stick" developmental water-based fluorocarbon (refs. 8,9), a second Dow coating and Freecom Ceram-Kote $54^{\mathrm{mM}}$, a commercial ceramic-epoxy coating used in petroleum, marine and sewage applications to protect against corrosion and erosion. Each of these was applied to the center 7.6-cm-wide band of one cylinder with a Teflon-filled paint (Deft Aliphatic Polyurethane Coating with Teflon, MIIL-C-83286B) applied to the top band and BFGoodrich Icex applied to the bottom band. Icex is a silicone-based product marketed as a coating for elastomeric deicing boots to reduce ice adhesion. It was not expected to perform well on aluminum. Ice accreted on the uncoated aluminum between the coated bands was also observed, the shape was recorded, and the ease of removal was noted as a reference for the coated-surface results.

Among these coatings, only the Dow "Anti-Stick" appeared to reduce the adhesion of ice compared with the uncoated surface. The Ceram-Kote 54 ${ }^{\mathrm{TM}}$ appeared to increase the adhesion. The Surface Seal'M, Icex and Teflon paints all performed about the same as the uncoated aluminum. Although the Teflon provides a very slippery surface with high water repellency, it also has a high pore density which probably encourages strong mechanical bonding with the ice.

Figure 1(b) shows the cylinder with ice accreted. For this test, the center band was coated with Dow "Anti-Stick." As for all the tests, the top band had the Teflon paint and the bottom, Icex. There was no evident effect of the coating on either the quantity of ice accreted or its appearance.

This observation was confirmed by comparing tracings of the ice shape formed on the coated bands and the uncoated part of the cylinder. Two examples of such tracings are shown in Figure 2. Figure 2(a) gives ice shapes resulting from tests with a droplet median volume diameter (MVD) of $15 \mu \mathrm{m}$, and Figure 2(b) gives shapes for an $M V D$ of 40 $\mu \mathrm{m}$. At each of the two test conditions, the surface coating had no effect on the final ice shape. The small differences between the ice shapes in each figure were typical of the variations produced by the IRT cloud nonuniformity. These results were consistent with those of Hansman and
Turnock ${ }^{10}$ who also found that ice shapes were independent of the material on which accretion occurred.

Studies using high-magnification images (references 11 and 12) have shown that water coalesces into beads during glaze-ice accretion. Because of this, if the beading process is altered, one could expect the final ice shape to change. The lack of a surface effect in this study can be understood by considering that once a thin layer of ice has formed over the model, water impinging and freezing will see only the ice surface; any substrate effects are totally masked. ${ }^{12}$

Although these cylinder tests provided a standardized test fixture they gave only a subjective evaluation of the difficulty of removing ice from the cylinder. Some of these same coatings were also tested with the BFGoodrich parallel-plate shear apparatus to establish quantitative results.

BFGoodrich Parallel-Plate Shear Tests This test apparatus has been discussed in reference 3. Figure 3 is a sketch which illustrates the test method. Static ice was frozen in a thin layer (about $1.8 \mathrm{~mm}(.07 \mathrm{in})$ ) between a movable pedestal and a stationary platform. Both surfaces were cooled by circulating a refrigerated alcohol solution through the pedestal support and the platform. Freezing took 1 - 2 minutes, but the ice was allowed to stabilize for 3 minutes before applying force. A gear motor drove the linear stage on which the pedestal was mounted, and the force was measured with a load cell. The adhesion strength of the ice to the surface was found by dividing the force required to shear the ice, $F$, by the surface area, $A$, with small corrections for the stress concentration.

The coatings tested on the 7.6-cm-diameter cylinder in the IRT, the "Anti-Stick" Surface Sealm and Ceram-Kote $54^{\mathrm{TM}}$, were also tested in the BFGoodrich shear test stand. Figure 4 gives the adhesive strength of static ice on the three coatings and on the uncoated aluminum substrate. Results are given for 20 repeated ice removals. A linear regression fit has been made for each set of data. It is evident that the Dow coating displayed fairly repeatable adhesive strength which increased little with number of ice removals. However, these data are not sufficient to prove the long-term durability of the coating. The Surface Sealm gave highly variant results from test to test and appeared to show increasing adhesive force with time. An explanation for this type of variability has been proposed by Reich ${ }^{3}$. It should be noted that Surface Seal has shown excellent durability and effectiveness as a hydrophobic coating for aircraft windshields, but was not developed as a coating for aluminum. Ice adhered more strongly to the Ceram-Kote $54^{\mathrm{TM}}$ than to the uncoated aluminum surface.

Impact ice, such as that resulting from the IRT experiments, has different physical characteristics from the 
static ice of the BFGoodrich shear-rig tests. Nevertheless, the quantitative shear results were fully consistent with the qualitative IRT observations. This consistency tends to confirm the validity of the static-ice shear-test method as a simple but meaningful screening technique. Once promising coatings have been identified with static ice, follow-up tests in an icing tunnel can be made to check results with impact ice.

University of Akron Shear Rig in IRT In an effort to obtain quantitative results with impact ice in the IRT, the shear test rig developed by Scavuzzo and $\mathrm{Chu}^{5,6}$ of the University of Akron to measure ice properties was used in the next series of tests. This device is sketched in figure 5. It used 2.5-cm- (1-in-) diameter cylinders coated with the test material and mounted inside a thin sleeve. Five of these cylinder-sleeve combinations were mounted vertically on a support rod for testing at one time. A window was cut from the sleeve to expose a portion of the coated cylinder to the icing cloud. Ice accreting on the sleeve bonded the cylinder to the sleeve at the window. The test rig was originally designed with a motor drive to rotate the vertical assembly at a steady speed during ice accretion. For these tests, the assembly was fixed in such a way that the sleeve window faced into the icing spray. Once ice was accreted, each cylinder-sleeve assembly was carefully removed and placed on a stand where the cylinder was forced through the sleeve with a hydraulic press acting through a load cell. The force required to free the cylinder was recorded on a strip chart.

Unfortunately, this test method had two major problems. First, ice sometimes caused adjoining cylinder-sleeve assemblies to stick together making disassembly difficult. Second, the cylinders often separated from the sleeves when they were removed from the ice-accretion portion of the test stand. This was a particular problem with low-adhesion coatings, and, as a result, for many tests no measurement could be obtained.

This method was used to test a number of coatings, but because of the problems noted above, the data obtained were not considered to be reliable, and the values recorded for shear force will not be reported.

For this and subsequent tunnel tests, the conditions were: static temperature, $-6^{\circ} \mathrm{C}\left(25^{\circ} \mathrm{F}\right)$, test-section airspeed, 67 $\mathrm{m} / \mathrm{s}(150 \mathrm{mph}), M N D, 20 \mu \mathrm{m}, L W C, .8 \mathrm{~g} / \mathrm{m}^{3}$ and spray time, $5.8 \mathrm{~min}$. These conditions provided a glaze-ice growth fairly normal to the surface with accretions thick enough to cover the window fully. Scavuzzo and $\mathrm{Chu}^{5}$ found that impact ice adhesion was fairly constant for temperatures below $-6^{\circ} \mathrm{C}\left(25^{\circ} \mathrm{F}\right)$ and decreased for higher temperatures. Thus, at the temperatures of these tests the adhesion would have been as high as might be expected. It's desirable to test with fairly high adhesion values to make it easier to discriminate between different results.
Stacked 2.5-cm-Diameter Cylinders To eliminate the necessity of removing the coated cylinders from the iceaccretion stand for force measurement, the Akron Shear Rig was used in a modified way for several tests. The coated cylinders were mounted on the support rod shown in Figure 5(a) but the windowed sleeves were not placed over them. Thus, the entire cylinder was exposed to the icing spray and, again, five coatings could be tested at once. A gap was melted in the ice between each cylinder at the completion of the icing spray to separate each ice formation. Initial tests (see Table 1, 5-4-95 entry) with this apparatus relied on a qualtitative assessment of the ease with which ice could be pushed from each cylinder. Later tests (10-31-95) used a hand-held force meter to detemine the force required to shear the ice from the surface.

Flat-Plate Only one test (10-31-95) was performed using a $1.3-\mathrm{cm}-(1 / 2$-in-) thick aluminum flat plate with a rounded leading edge. The leading edge was allowed to accrete ice which was then sheared with the hand-held force meter. Three diamond-like coatings from the University of Virginia were examined and found to reduce the adhesive strength of ice by up to $50 \%$ compared with an uncoated aluminum plate.

Multi-Blade Coating Tests in IRT and IWT A simple test stand was next designed to permit shear-force measurements of impact ice without disturbing the coated specimens. Each specimen was a 7.6-cm- (3-in-) long blade cut from 5-cm-by-.64-cm (2-in-by-1/4-in) aluminum bar stock as sketched in Figure 6(a). Ten, and later, fifteen of these blades were mounted on supports such that a flat 5-cm-by-.64-cm (2-in-by-1/4-in) coated edge faced the icing spray. This apparatus was tested in both the Lewis IRT and the BFGoodrich IWT. Figure 6(b) shows the rig installed in the IWT. When tested in the NASA-Lewis IRT, this mounting frame was located at the horizontal center of the test section. In each tunnel, the center supporting bar with its five blades was at the tunnel vertical midline.

The desired velocity and temperature were first established. Water spray was then initiated. The spray conditions and time of exposure produced an approximately $1.3-\mathrm{cm}-(1 / 2-$ in-) thick ice shape which grew nearly normal to the coated surface in the IRT. For the IWT tests, the accreted ice had a mushroom appearance in cross section with the edges somewhat rounded. At the completion of the test, the spray was shut off and the tunnel brought to idle to permit personnel entry into the test section to take measurements. A hand-held digital force meter was used to apply a load to the edge of the ice to shear it from the face of the test blade as shown in Figure 6(c). Force measurements were manually recorded. The adhesive strength was determined 
by dividing the recorded force by the face area, $3.2 \mathrm{~cm}^{2}(.5$ in $^{2}$ ) and applying a correction for stress concentration.

An analysis of stress concentration was not made for the present study; however, a reasonable value to use may be estimated from published sources. Scavuzzo and $\mathrm{Chu}^{5}$ performed a finite-element analysis on their shear-test geometry and found that an average stress concentration of approximately 2 could be applied. Reich applied an analytical solution for his parallel-plate shear ig $^{3}$ and plotted the ratio of the measured to the true adhesive strength as a function of the ratio of the ice thickness to the sample length. In the present tests, the ice thickness was about $1 \mathrm{~cm}(1 / 2$ in), and the length of sample was $5 \mathrm{~cm}$ (2 in). For a ratio of thickness to length of $.2-.25$, the stress concentration from Reich's plot is about 1.3. Because of the manner in which force is applied in the multi-blade tests, the stress concentration can be expected to be higher than that found from Reich's plot; thus, the value of 2 from Scavuzzo and Chu was thought to be more probable, and even this may be conservative. Thus, all multi-blade data reported here have had a factor-of-2 stress concentration applied.

Figure 7 compares the adhesive strength of impact-ice with that of static ice. Both types of ice were accreted on uncoated aluminum surfaces. The impact-ice data are from IWT tests using the multi-blade stand shown in Figure 6(b). An uncoated blade was mounted in the center of each of the horizontal support bars. The three sets of data represent the blade at the top, at the middle and at the bottom support bar. Adhesion values from the top and bottom bars were about the same, while the center bar produced adhesive strengths about $20 \%$ higher than the other two. A possible explanation for this difference is the proximity of the top and bottom bars to the ceiling and floor of the tunnel. It is possible that temperatures at these positions were higher than at the center, and, if so, the resulting adhesive strength would be reduced relative to the center bar. Temperature measurements in the IWT were not taken to so it is not known if temperature gradients exist in that tunnel.

The dotted line in Figure 7 gives the average adhesive strength found in reference 3 for static ice on uncoated aluminum. The value was close to the initial impact-ice results from the center bar of the multi-blade test. It was shown above that the qualitative rankings for various coatings was the same from the static-ice shear rig and the 7.6-cm cylinder impact ice tests. The comparison in Figure 7 now also shows fairly good quantitative agreement between static-ice and impact-ice tests, although there is some uncertainty in the correct stress concentration for the latter results.
Figure 8 shows the results of a series of IRT tests with the multi-blade rig using experimental polymers produced by Elastic Ceramic Coatings. In each test, an uncoated blade was mounted in the center of each bar as a reference, and the adhesive strength from the uncoated blade is reported for comparison with the coated results. The coatings for which the ice adhesion strength is shown in Figure 8 were applied to blades mounted on the same support bar, thus, the adhesion strengths for the uncoated reference are the same for both coatings. Results for coating $7 B$ are given in Figure 8(a) and for coating 8B, Figure 8(b). For these coatings, the adhesive strength of ice was initially about half that of the uncoated aluminum with a few individual results even lower. The adhesive strength increased as ice was repeatedly removed until the sixth removal when adhesion approached that of the uncoated blade. Clearly, these coatings do not have adequate durability at this time. The coated samples displayed less variation from test to test than the uncoated.

Figure 9 shows adhesion strengths for a fluoropolymerbased Du Pont coating, one of a number of coatings tested with the multi-blade rig in the IWT. The same coating was applied to two blades to determine possible effects of variability of the application procedure. The two blades were initially mounted on the top support bar. After 9 ice removals, the first blade was moved to the middle support, and testing with the second blade was terminated. For the first 9 removals, both coated-blade results are compared with the uncoated-aluminum reference blade on the top support bar. For removals $10-17$, the uncoated reference was on the center bar.

Figure 9(a) shows ice adhesion strength for 17 ice-removal tests with the first blade; and Figure 9(b), adhesion strength for the 9 removals on the second blade. Both applications gave adhesion strengths about half that from the uncoated reference. There did not appear to be any dramatic change in the adhesive strength when the first blade was moved from the top to the middle bar. For 17 ice removals, the linear regression fit through the data was nearly flat; this result suggests the possibility of good durability.

Consistency between the tests performed in the BFGoodrich IWT and the NASA Lewis IRT can be seen in the uncoated-blade data in Figures 8 and 9. In both tunnels, the average impact-ice adhesive strengths for uncoated aluminum were in the range of $7-9 \times 10^{5} \mathrm{nt} / \mathrm{m}^{2}(100-130$ psi).

\section{Concluding Remarks}

This paper reviewed several years' testing of low-iceadhesion coatings. Test methods started with simple qualitative tests in the NASA Lewis Icing Research Tunnel 
(IRT) comparing the relative ease of impact ice removal from coated and uncoated surfaces. Coatings which appeared to have potential for significant reductions in ice adhesion were also tested with static ice in a BFGoodrich shear rig. Methods to obtain shear-force measurements with impact ice in the IRT and the BFGoodrich IWT were described with results for some of the coatings.

It was apparent from these tests that the amount and shape of the ice accreted in the wind tunnel were dependent solely on tunnel and cloud conditions, not on the surface on which the ice accreted. Although the shape of the ice accreted is dependent on surface effects such as water beading and runback, soon after the start of exposure to the icing cloud, the coated surface becomes covered with a layer of ice; subsequent accretion occurs on a surface of ice, whose interaction with water is the same regardless of the original substrate characteristics.

Results from tests with hydrophobic coatings is of interest because this class of materials has at times been proposed as having icephobic characteristics. One of the hydrophobics tested was intended for use on glass, not aluminum, and it gave no reduction in shear adhesion on aluminum. Results for this type of material were inconclusive, but it would appear that hydrophobicity does not necessarily produce icephobicity.

Of particular note, the test results showed consistency between impact-ice tests in icing tunnels and a static-ice shear test. It appears to be possible to reach valid conclusions about the shear strengths of impact ice on coated surfaces by performing static-ice tests. Additional tests to validate the static-ice approach should be undertaken, however. The static-ice test is simpler and considerably less expensive to perform than a tunnel test; it makes sense, then, to conduct future screening programs with a static-ice shear test. After ranking coatings in this way, those coatings showing particular promise should also be tested in a tunnel with impact ice.

\section{References}

1. Loughborough, D.L. and Haas, E.G., "Reduction of the Adhesion of Ice to De-Icer Surfaces," J Aeronautical Sciences, March, 1946, pp126 - 134.

2. Loughborough, D.L., "The Physics of the Mechanical Removal of Ice from Aircraft" Aeronautical Engineering Review, vol 2, February, 1952, pp29 - 34.

3. Reich, A., "Interface Influences Upon Ice Adhesion to Airfoil Materials," AIAA-94-0714, January, 1994.

4. Reinmann, John J., private communication, 1992.
5. Scavuzzo, R.L. and Chu, M.L., "Structural Properties of Impact Ices Accreted on Aircraft Surfaces," NASA Contractor Report, CR-179580, January, 1987.

6. Scavuzzo, RL., Chu, M.L. and Kellackey, C.J., "Structural Analysis and Properties of Impact Ices Accreted on Aircraft Structures," NASA Contractor Report, CR198473, April, 1996.

7. Soeder, Ronald H., Sheldon, David W., Andracchio, Charles, R., Ide, Robert F., Spera, David A. and Lalli, Nick M. "NASA Lewis Icing Research Tunnel User Manual," NASA TM 107159, June 1996.

8. Schmidt, Donald L., McCrackin, Perry J. and Coburn, Charles E., "Fluorocarbon Containing, Reactive Polymeric Surfactants and Coating Compositions Therefrom," Patent No. 4,929,666, May, 1990.

9. Schmidt, Donald L., Coburn, Charles E. and McCrackin, Perry J., "Fluorocarbon Containing, Reactive Polymeric Surfactants and Coating Compositions Therefrom," Patent No. 5,006,624, April, 1991.

10. Hansman, RJ., Jr and Turnock, S.R., "Investigation of Surface Water Behavior During Glaze Ice Accretion," J Aircraft 26, no 2, February 1989, pp 140-147.

11. Olsen, W.A. and Walker, E., "Experimental Evidence for Modifying the Current Physical Model for Ice Accretion on Aircraft Structures," NASA TM87184, 1987.

12. Hansman, R., Breuer, K.S., Hazan, D., Reehorst, A. and Vargas, M., "Close-up Analysis of Aircraft Ice Accretion," AIAA-93-0029, January, 1993. 


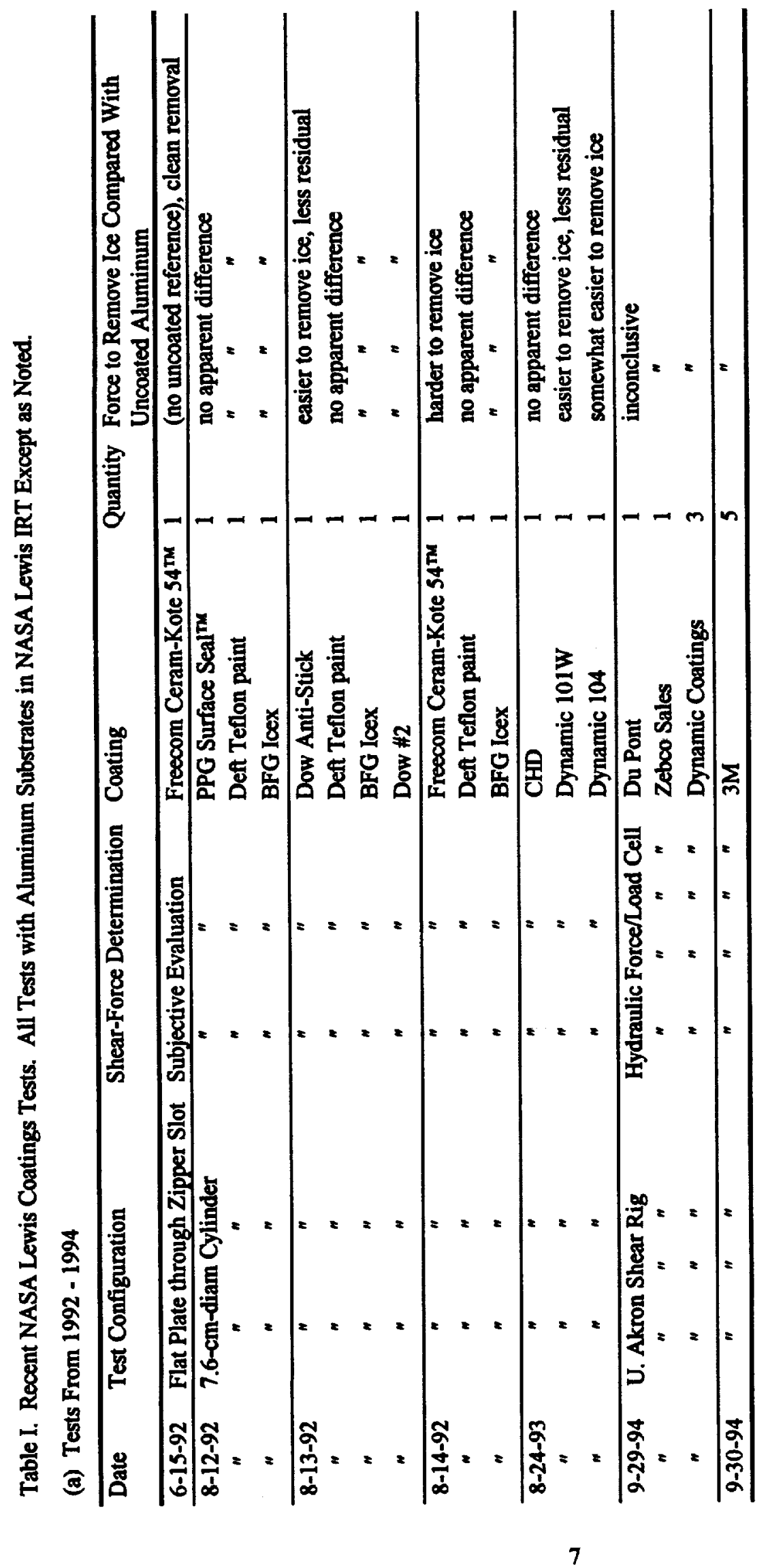




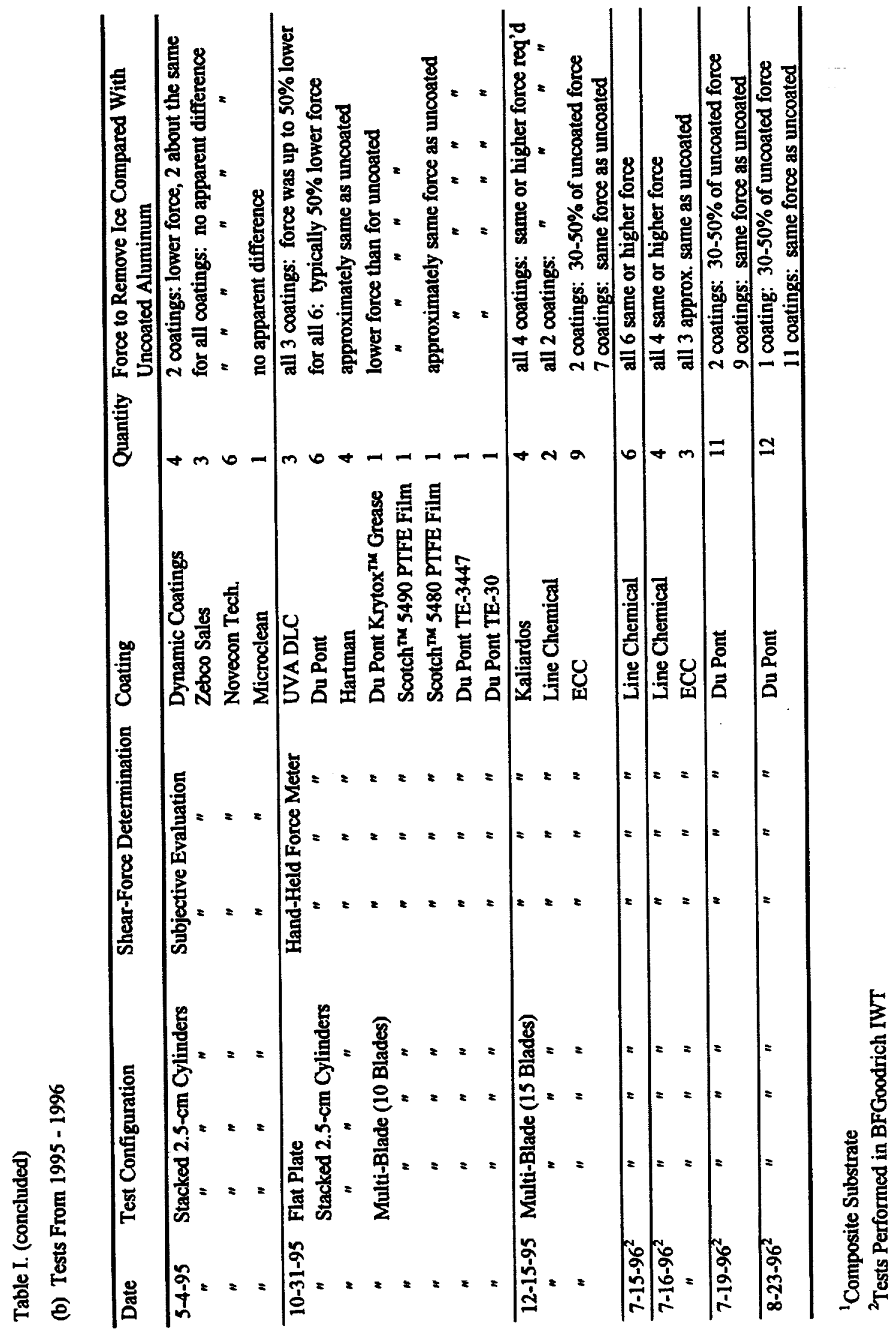




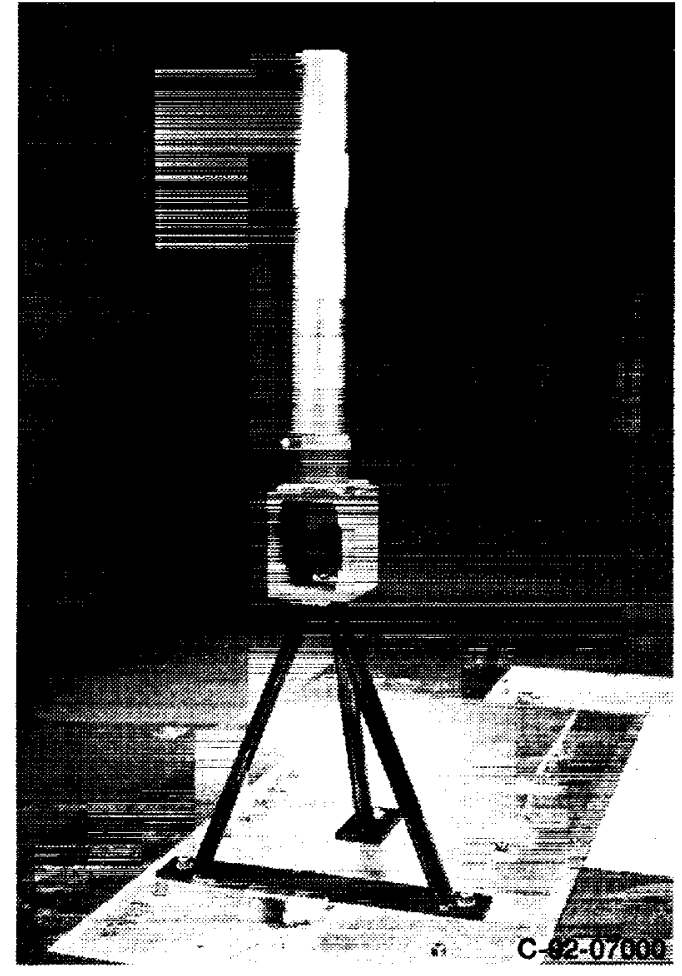

(a) Test Cylinder Mounted in Test Section.

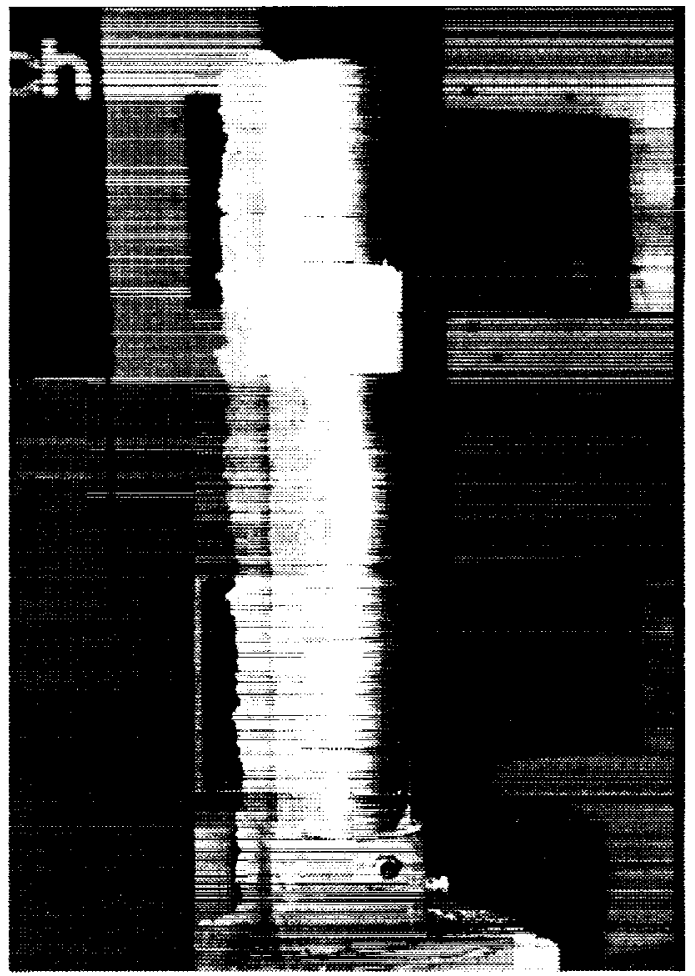

(b) Ice Accreted Over Coated Bands.

Figure 1. Coatings Tests Using 7.6-cm- (3-in-) Diameter Cylinder in IRT. Width of Coated Bands, $7.6 \mathrm{~cm}$ (3 in).

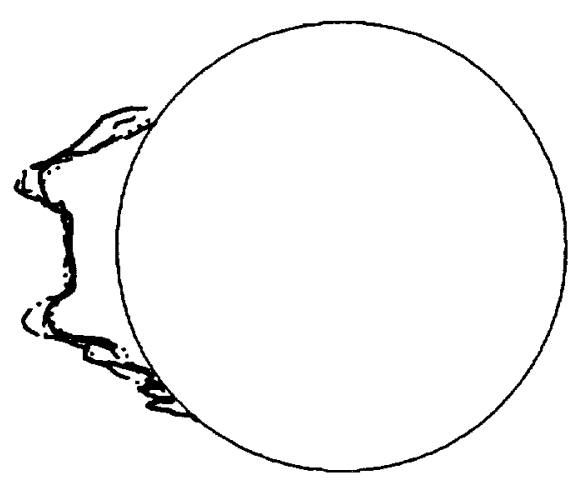

(a) $M V D, 15 \mu \mathrm{m}$.

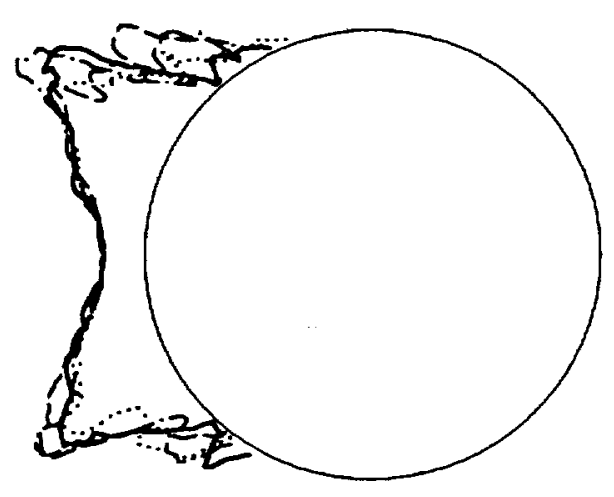

(b) $M V D, 40 \mu \mathrm{m}$.

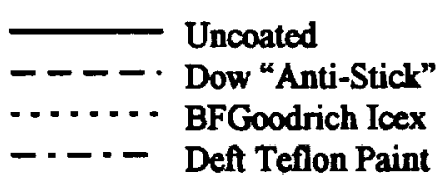

Figure 2. Ice Shapes Observed for Various Surface Treatments. Static Temperature, $-10^{\circ} \mathrm{C}\left(14^{\circ} \mathrm{F}\right)$;

Velocity, $112 \mathrm{~m} / \mathrm{s}$ (250 mph); $L W C, .5 \mathrm{~g} / \mathrm{m}^{3}$; Spray Time, $10 \mathrm{~min}$. 


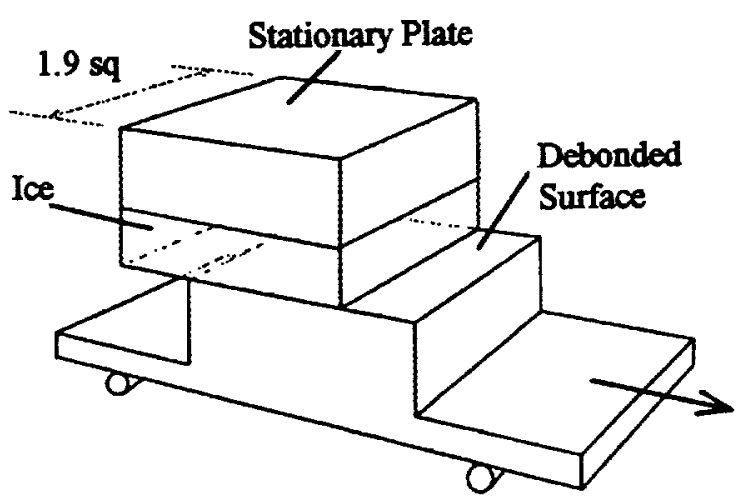

Figure 3. BFGoodrich Parallel-Plate Shear Rig. Dimensions in $\mathrm{cm}$.

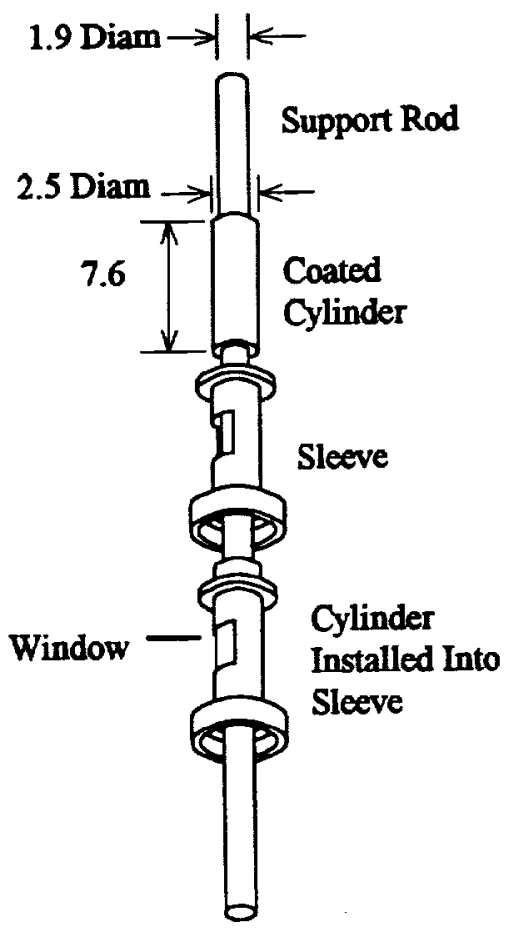

(a) Details of Cylinder and Sleeve Assembly.

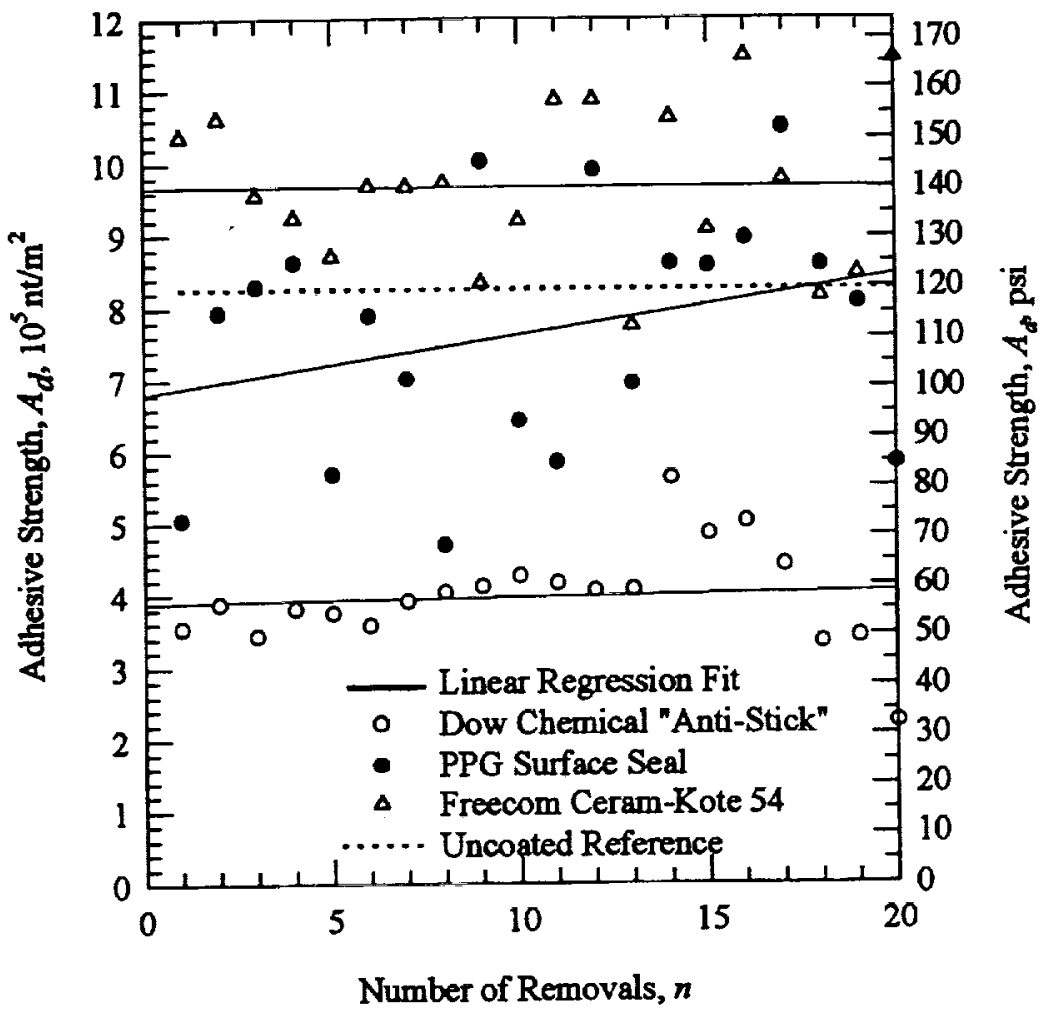

Figure 4. Adhesion Strength of Static Ice on 3 Coatings. Tests Using BFGoodrich Parallel-Plate Shear Rig.

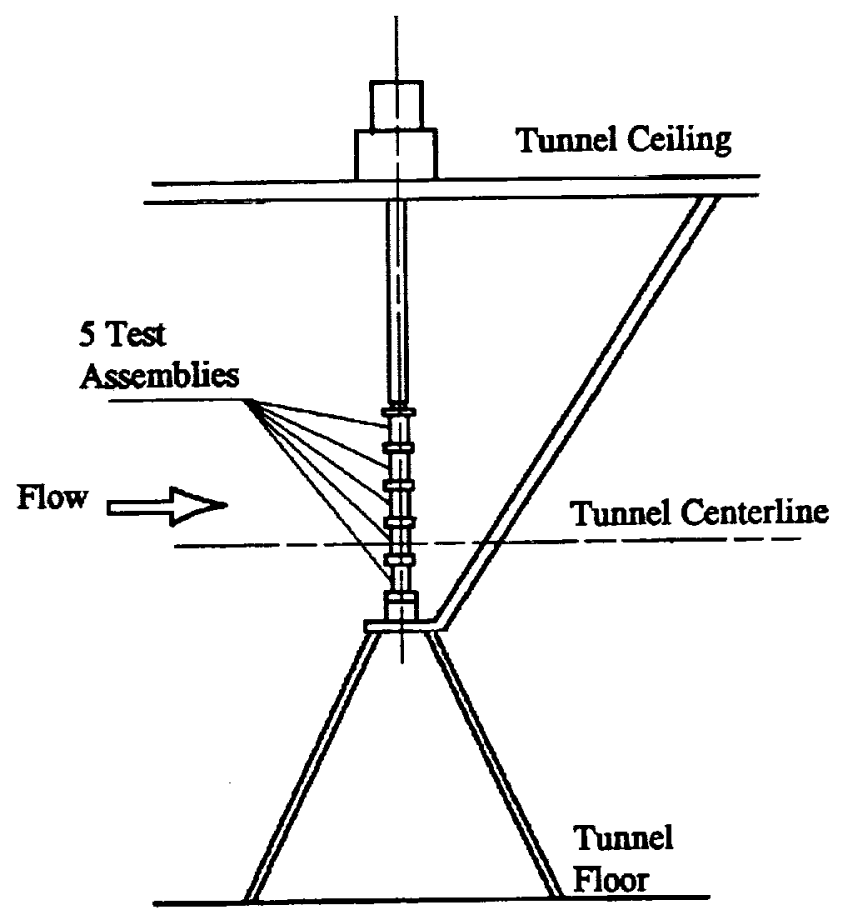

Figure 5. University of Akron Shear Rig. Dimensions in $\mathrm{cm}$. 


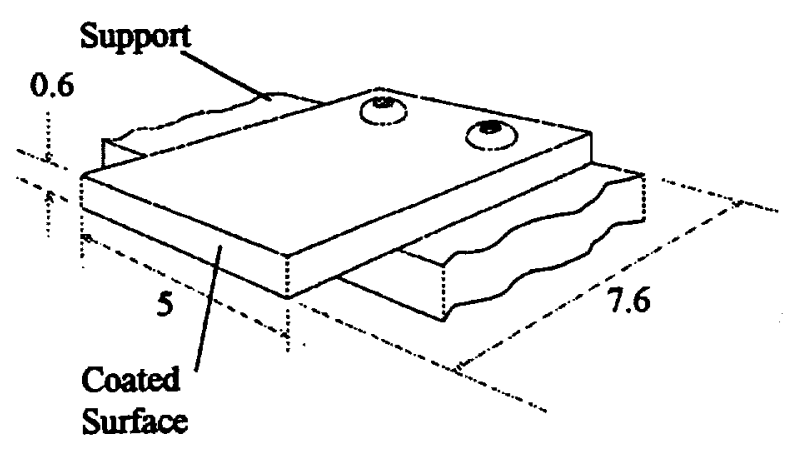

(a) Close-up View of Blade. Dimensions in $\mathrm{cm}$.

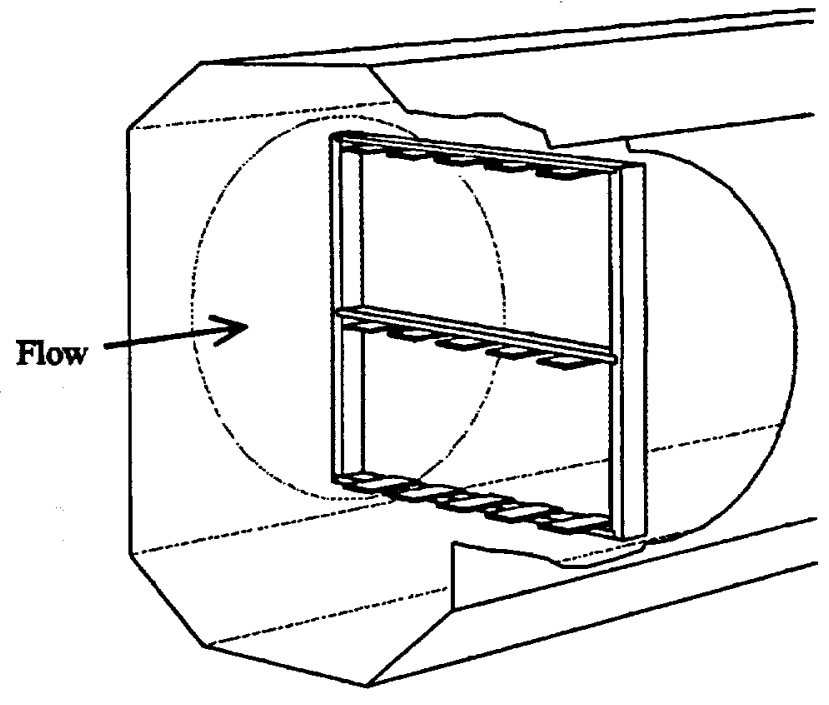

(b) Test Stand Assembly in BFGoodrich IWT.

Figure 6. Multi-Blade Coatings Test.
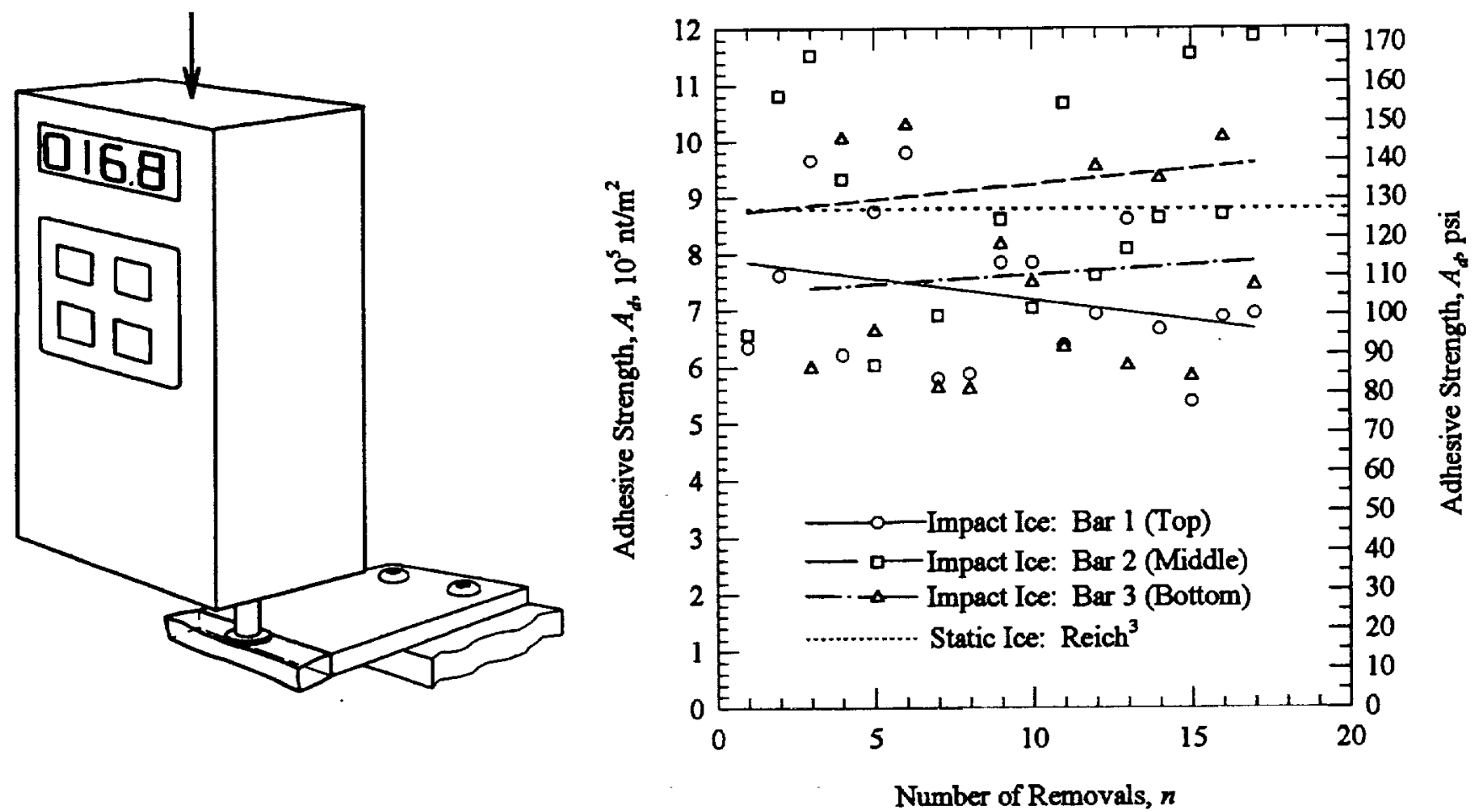

(c) Digital Force Meter Applied to Ice

Figure 6. (concluded)

Figure 7. Comparison of Impact-Ice and Static-Ice Shear Measurements on Uncoated Aluminum. Impact Ice Data From Multi-Blade Test in IWT; Static-Ice Results From BFGoodrich Parallel-Plate Shear Rig ${ }^{3}$. 


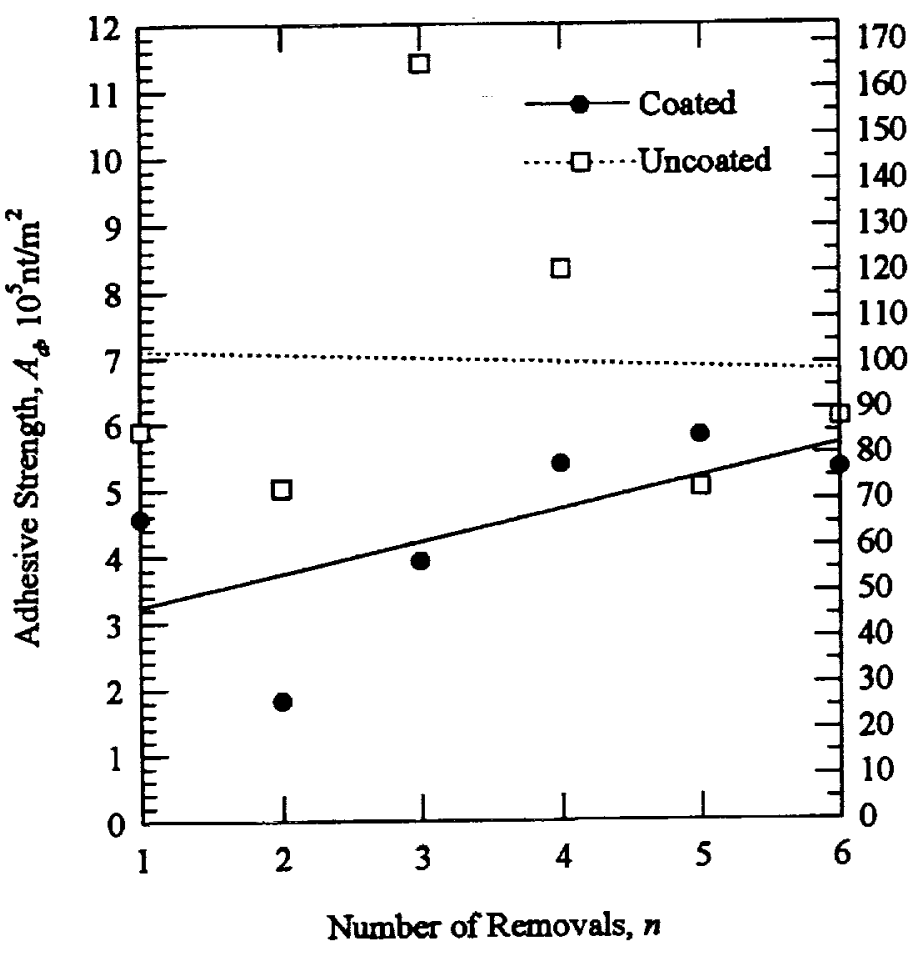

(a) Coating $7 \mathrm{~B}$.

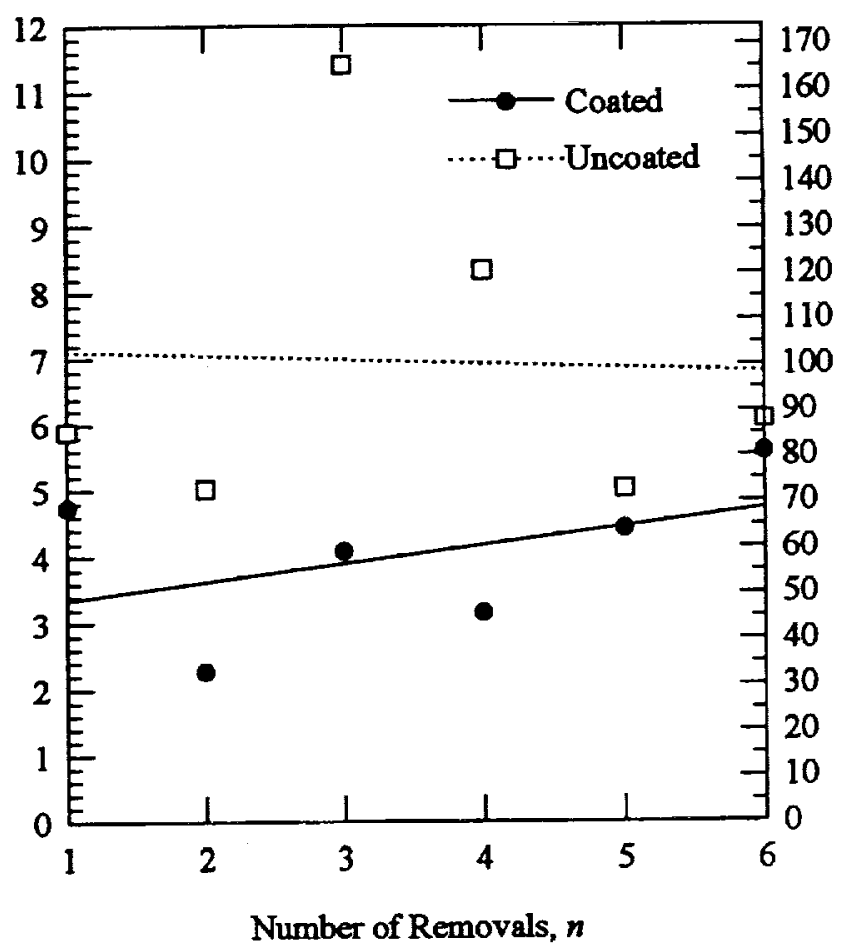

(b) Coating 8B.

Figure 8. Elastic Ceramic Coatings Results Using Multi-Blade Test Stand in NASA Lewis IRT.

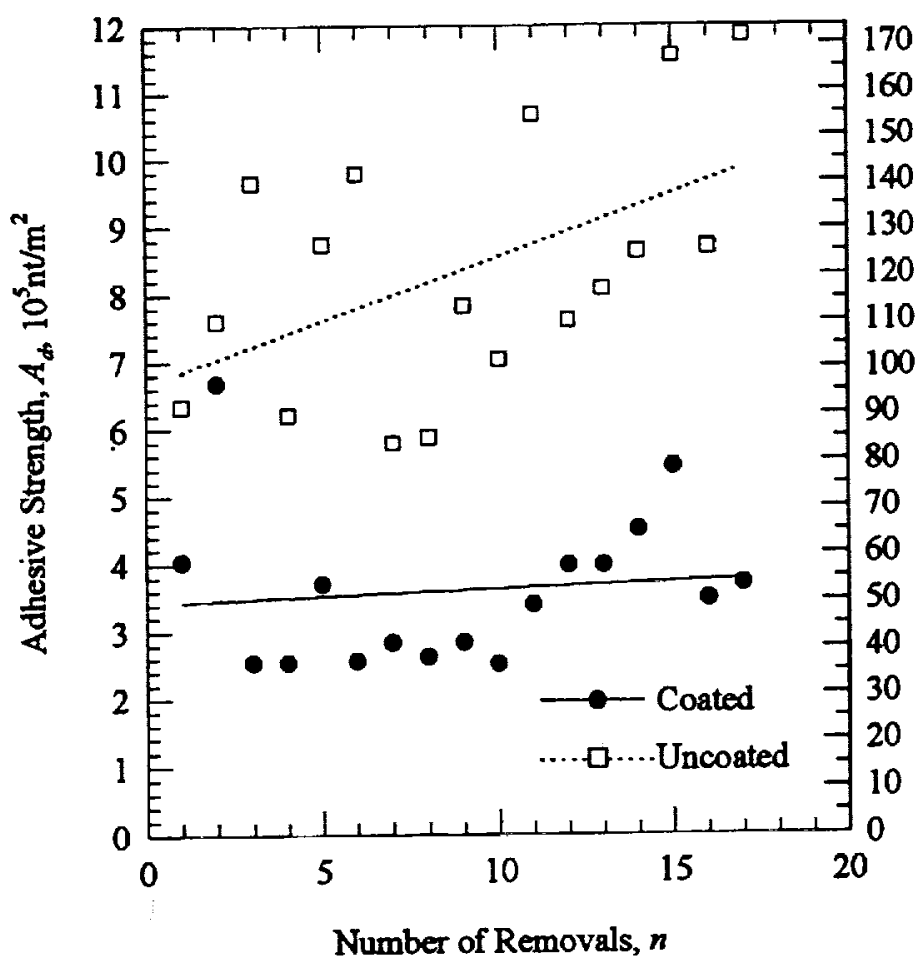

(a) Coating 1 Applied to First Blade.

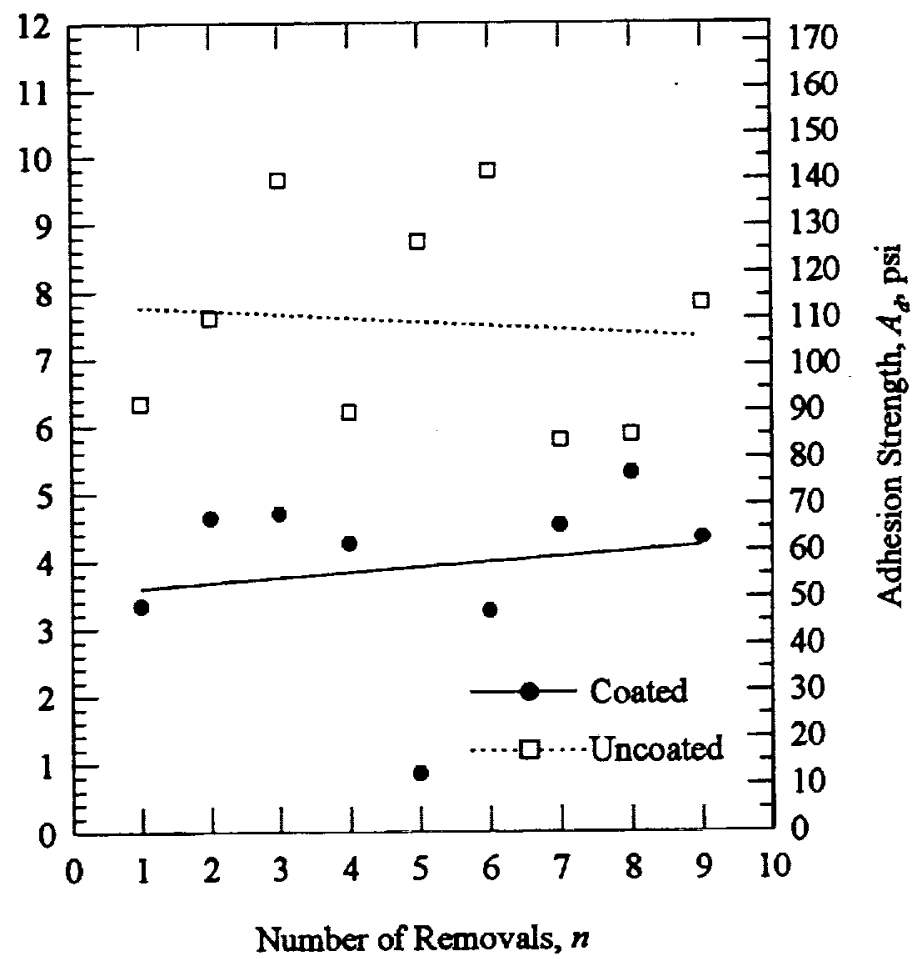

(a) Coating 1 Applied to Second Blade.

Figure 9. Du Pont Coating 1 Results Using Multi-Blade Test Stand in BFGoodrich IWT. 


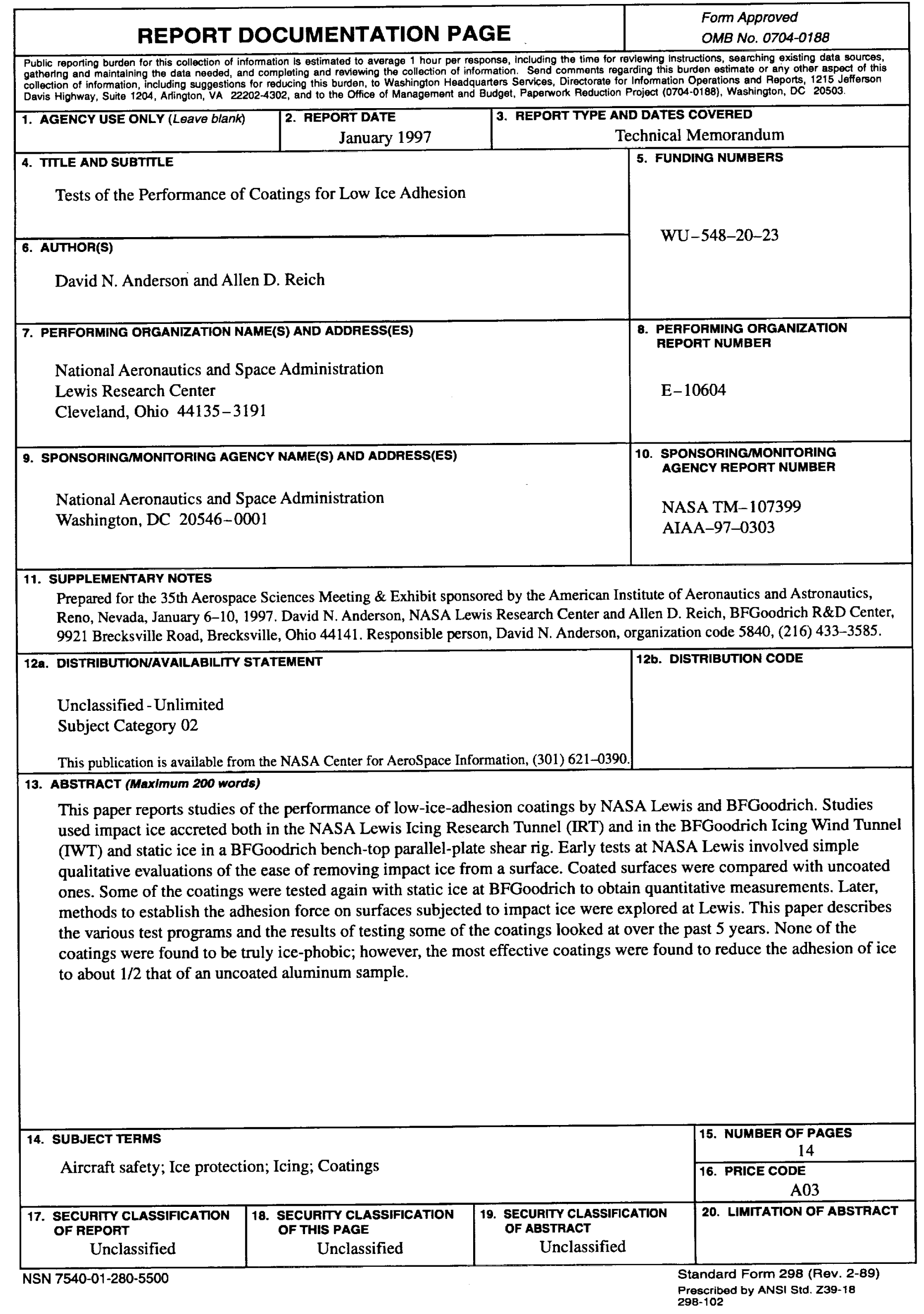




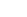

